\title{
Unexpected public health consequences of the COVID-19 pandemic: a national survey examining anti-Asian attitudes in the USA
}

\author{
Lindsay Y. Dhanani ${ }^{1} \cdot$ Berkeley Franz ${ }^{2}$
}

Received: 27 May 2020 / Revised: 8 July 2020 / Accepted: 14 July 2020 / Published online: 29 July 2020

(C) Swiss School of Public Health (SSPH+) 2020

\begin{abstract}
Objectives This paper empirically examines whether and how COVID-19 may be activating bias and discrimination toward individuals of Asian descent.

Methods In March 2020, we used a national online survey to collect data from 1141 US residents. Using descriptive statistics and multivariate regression, we estimated the prevalence and COVID-19-related predictors of bias toward people of Asian descent.

Results We found over $40 \%$ of our sample reported they would engage in at least one discriminatory behavior toward people of Asian descent. Respondents who were fearful of COVID-19 $(b=.09, p<0.001)$ and had less accurate knowledge about the virus $(b=-.07, p<0.001)$ reported more negative attitudes toward Asians as did respondents with less trust in science $(b=-.06, p<0.001)$ and more trust in President Trump $(b=.04, p<0.001)$.

Conclusions Public health leaders must confront fear of the virus, improve knowledge, and bolster trust in science as these factors may evoke negative attitudes toward Asians and increase prejudice and discrimination. Specifically, our findings warrant the adoption of public health campaigns that provide health information and build trust in scientific knowledge.
\end{abstract}

Keywords COVID-19 $\cdot$ Bias $\cdot$ Prejudice $\cdot$ Asians

\section{Introduction}

The novel coronavirus (COVID-19) emerged in the late months of 2019 in Wuhan, China, and has since spread to nearly every country across the globe. In the few months since COVID-19 was first identified, over 11.5 million people have been infected and the death toll is currently estimated at over 500,000 people-a figure that continues to climb (Johns Hopkins University and Medicine 2020). The emerging outbreak has also disrupted nearly every aspect of our social lives as the public has been asked to

Lindsay Y. Dhanani

dhanani@ohio.edu

Berkeley Franz

franzb@ohio.edu

1 Department of Psychology, Ohio University, 22 Richland Avenue, Athens, OH 45701, USA

2 Department of Social Medicine, Heritage College of Osteopathic Medicine, Ohio University, Grosvenor 311, Athens, OH 45701, USA take substantive measures to stem transmission of the virus (Centers for Disease Control and Prevention 2020). Beyond the human, social, and economic toll of the virus, however, is evidence that this pandemic may be activating bias and discrimination toward individuals of East Asian descent (Loffman 2020). The goal of the current study is therefore to explore negative attitudes toward people of Asian descent in the wake of COVID-19 as well as identify what factors predict these anti-Asian sentiments. Our contribution is unique in that it provides an empirical examination of how COVID-19 activates bias toward Asians and has implications for how public health campaigns can limit bias and discrimination associated with infectious disease outbreaks.

\section{COVID-19 and anti-Asian prejudice}

As knowledge of COVID-19 has increased, world leaders have emphasized the connection between the virus and its country of origin, and people of East Asian descent have felt the ensuing ramifications, especially in Western 
countries (Marquardt and Hansler 2020). In the USA, one of the first signs of changing sentiments was customers vacating Chinatowns as COVID-19 cases increased (Chang 2020). Initial avoidance, however, has grown into open hostility, and Americans of Asian descent have reported a growing fear of being in public because of the harassment they have experienced or witnessed in response to COVID19 (Tavernise and Oppel 2020). Documenting the extent of this issue, a researcher at San Francisco State University created a Website to capture Asian Americans' experiences of harassment and discrimination and received over 650 reports of discrimination within the first 8 days of the Web site being established (Mullis and Glenn 2020). Further, a recent study conducted by the Pew Research Center found that nearly $40 \%$ of Americans believe racism against Asian Americans has become more common since the onset of the COVID-19 outbreak and nearly one-third of Asian Americans reported being the target of racist slurs or jokes because of the virus (Ruiz et al. 2020). It is critical to understand the experiences of people of Asian descent amid the COVID-19 pandemic because they may be experiencing what researchers call a double burden such that they must simultaneously fear for their health while also enduring racial backlash and discrimination (Leung and Guan 2004).

Though the increase in prejudice in response to COVID19 is impactful and worthy of study, it is also important to recognize that similar biases have been observed following other infectious disease outbreaks (Goodwin et al. 2009; Khan et al. 2016). Indeed, evidence of pandemics triggering bias dates back at least to the 1918 influenza outbreak. Despite not originating in Spain, the virus became known as the "Spanish flu" which led to stigmatization of Spanish nationals (Hoppe 2018). Similarly, there was an outbreak of the bubonic plague in India in 1994 and, despite being localized to one region, the stigma of the disease led to many countries banning travel and imports from the entire nation (Barrett and Brown 2008). More recently, the 2009 H1N1 outbreak, which originated in Mexico, was accompanied by a rise in stigma against Mexicans and other people of Hispanic descent across the USA (McCauley et al. 2013). Asian Americans and Asian Canadians have also previously been the target of disease-related stigma after the 2003 outbreak of Severe Acute Respiratory Syndrome (SARS) was linked to China (Lee and Murphy 2003; Person et al. 2004; Eichelberger 2007). These accounts highlight the powerful effects of public health crises on prejudice and discrimination toward out-groups which we are again seeing in response to COVID-19.

\section{Predictors of anti-Asian prejudice amid the COVID-19 pandemic}

We draw on theories of intergroup threat to propose that fear and knowledge of COVID-19 may predict bias toward Asian Americans. Theorists have long recognized the importance of social identities for individual self-concepts and intergroup relations (Tajfel and Turner 1986; Stephan et al. 2009). Identifying with social groups provides numerous psychological benefits (Allport 1954), but this same identification is accompanied by the cost of engendering intergroup conflict. According to intergroup threat theories, this is particularly true when out-group members are perceived to pose a threat to the in-group, and such perceptions may arise when an out-group is seen as threatening to the well-being or goals of one's in-group, is competing with the in-group for limited resources (Sherif and Sherif 1969), or may otherwise cause harm to the ingroup (Stephan et al. 2009).

Through the lens of intergroup threat theory, we propose the recent COVID-19 outbreak may be activating perceptions that people of Asian descent pose a threat to the wellbeing of others. Asian Americans in particular may prime intergroup threat because of the continued association of the virus with the initial outbreak in China. Given both the severity of the physical health consequences and economic damage associated with the virus, the result of this association is that Asian Americans may be perceived as threatening both the physical and economic health of others. We therefore hypothesize that general fears of COVID19 as well as feeling unsafe around Asian populations will be positively related to bias toward Asian Americans.

We also posit that more accurate knowledge of the virus may decrease the likelihood that people will associate the risk of infection with Asian Americans. This is because more accurate knowledge may increase one's understanding that transmission can occur when interacting with anyone who has been exposed to COVID-19. Indeed, there is evidence from the SARS outbreak that increased knowledge of the virus was associated with lower bias toward Asians (Des Jarlais et al. 2006). We draw on this to propose that more accurate knowledge will be associated with lower levels of bias.

Finally, trust in science and trust in President Trump may also shape anti-Asian American attitudes. Trusting scientists might increase exposure to messages that frame the virus in scientific terms, whereas trusting President Trump may increase exposure to messages that frame the virus in terms of its country of origin (e.g., referring to the virus as the "Chinese" or "Wuhan" virus) (Rogers et al. 2020). Downplaying science and emphasizing the Asian origin of the virus may serve to stoke bias toward out- 
groups-in this case Asian Americans. Correspondingly, we predict greater trust in science and lower trust in President Trump will be associated with more positive attitudes toward Asian Americans.

\section{Methods}

\section{Participants}

Our sample consisted of 1141 adults currently living in the USA. We collected data from a large sample because we wanted to ensure a broad, diverse sample of the American public. We calculated a post hoc power analysis using $\mathrm{G}^{*}$ Power. The estimation based on our obtained effect size and an alpha value of .05 suggested the obtained power for the study was 1.00 . Respondents were invited to participate in a survey related to knowledge and attitudes of the COVID-19 pandemic and were recruited via Qualtrics Panels. Qualtrics Panels is a professional participant recruitment service that is commonly used in the USA. This service distributes recruitment messages to potential participants using online platforms of registered and verified users. Participants who are interested and eligible are then provided access to the survey. This recruitment method offers the benefit of accessing participants from across the USA rather than being limited to a specific geographic region. The survey was open from March 13 to March 18, 2020, a time when widespread COVID-19 transmission within the USA was rapidly accelerating. The study was approved by the institutional review board at Ohio University, and informed consent was obtained from all participants before beginning the survey.

The participants who completed the survey resided in all 50 states and were diverse with regard to age, gender, and racial/ethnic identity. The average age of our participants was 44.66 years old $(S D=16.96)$ and ranged from 18 to 99. Slightly more than half of respondents were male $(52.1 \%)$. Females accounted for $46.9 \%$ of participants and $0.8 \%$ identified their gender as nonbinary or third gender. Further, $74.7 \%$ of the sample identified as White, $13.3 \%$ as Black or African American, 7.5\% as Hispanic or Latinx, $5.6 \%$ as Asian, $2.9 \%$ as American Indian or Alaskan Native, .6\% as Native Hawaiian or Pacific Islander, and $.5 \%$ as Middle Eastern. The racial composition of our sample closely resembles the US population with the exception that Hispanic individuals were underrepresented in our sample.

Participants were most likely to identify as heterosexual $(87.4 \%)$, whereas $12.6 \%$ identified as gay, lesbian, bisexual, or another sexual identity. With regard to education, participants were evenly distributed across educational outcomes with $22.3 \%$ reporting a high school diploma or
GED, $23.5 \%$ reporting college attendance but no degree, $13.3 \%$ holding an Associate's degree, $23.5 \%$ holding a Bachelor's degree, $13.6 \%$ holding a Master's degree, and $3.7 \%$ holding a doctoral or professional degree. Participants also represented different political affiliations with $43.5 \%$ identifying as democrats, $28.9 \%$ identifying as independents, and $27.6 \%$ identifying as republicans.

\section{Measures}

Participants were asked about a variety of topics related to COVID-19, including their fear of contracting the virus, knowledge of the virus, their level of trust in governmental leadership and science, their level of comfort with individuals from four countries with high infection rates, their attitudes toward people of Asian descent, and their demographics. Knowledge about COVID-19 was assessed by asking participants a series of questions (24 items in total) about how the virus is transmitted (six items), common symptoms of the virus (eight items), and other general information about its origin and treatment (ten items). Given that no validated measures had yet been generated to assess knowledge about COVID-19, we created this composite measure by adapting previously used items to gauge knowledge about infectious disease pandemics such as the H1N1 outbreak in 2009 (Di Giuseppe et al. 2008). To adapt the existing measures, we consulted Web sites created by national and international public health organizations aimed at correcting misinformation related to COVID-19 and generated items to cover the breadth of information contained within these Web sites and fact sheets (Maragakis 2020; World Health Organization 2020). Specific items included the current mortality rate, the existence of a cure or vaccine, whether the virus can be prevented by the pneumonia vaccine, and the origin of the virus. Questions related to COVID-19 transmission included what methods help prevent spread, such as washing hands and disinfecting surfaces. Participants were also asked to identify common symptoms of COVID-19 from a checklist of symptoms.

We measured trust in informational sources by asking participants to rate their trust in science/scientists and their trust in President Trump on a scale from 0 (no trust) to 10 (complete trust). This method is often referred to as a feeling thermometer and is commonly used to assess attitudes toward groups of people, political figures, and institutions (Hetherington 1998; Miller et al. 2004; Lavrakas 2008). Further, we chose to focus on trust in these two sources because they represent different sources from which to receive information related to COVID-19 and because some early debates have emerged between scientists and President Trump regarding the framing of the virus (Marquardt and Hansler 2020). 
We asked participants to respond to additional feeling thermometers that assessed fears surrounding COVID-19 in two ways. First, we asked participants to report their general concern of infection on a scale of 1 (no fear) to 10 (extreme fear). Second, to examine whether that fear was specifically associated with Asian populations, we also asked participants how safe they felt with individuals from China, South Korea, Iran, and Italy on a five-point scale ranging from 1 (very unsafe) to 5 (very safe). These countries were chosen because they represent the two Asian countries and two non-Asian countries with the highest confirmed cases of COVID-19 at the time of data collection in mid-March. Measuring feelings of safety in this way allowed us to capture how closely people associated fear of contracting the virus with people of Asian descent rather than people from other countries, despite similar levels of risk.

To create a single variable that captured relative feelings of safety, we calculated a mean score for feelings of safety around people from China and South Korea and a mean score for feelings of safety around people from Iran and Italy. A difference score was then computed by subtracting the mean score for the non-Asian countries from the mean score for the Asian countries. Negative difference scores reflect feeling less safe around people from China and South Korea in comparison with people from Italy and Iran.

We measured bias toward people of Asian descent with a scale comprising four questions asking participants about their likelihood (ranging from extremely likely to extremely unlikely) of interacting with people of Asian descent in a variety of contexts. Specifically, participants were asked if they would order food from a restaurant with primarily Asian employees, sit next to an Asian person on a bus or other public transportation, attempt to limit interactions with Asian customers or coworkers, or intentionally move farther away from an Asian individual while in a public place. We chose to focus on these behaviors because they align with early reports of Asian Americans' experiences in response to COVID-19. The scale demonstrated adequate reliability $(\alpha=.78)$, and results from a one-factor confirmatory factor analysis demonstrated good fit $\left(\chi^{2}\right.$ $(2)=21.38, \quad p<.001, \quad$ CFI $=.99, \quad$ TLI $=.98$, SRMR =.02).

It is important to note that some of the behaviors included in our scale align with general social distancing recommendations insofar as individuals may wish to avoid close contact with all individuals, not just Asians. Our data, however, were collected before states began to recommend social distancing and state-at-home orders. To better ensure that the relationships tested in this model are not reflecting people's general desires to avoid contact with others, we also measured and controlled for individuals' general social distancing efforts. We did so by asking participants if they have modified their behaviors in any way to protect themselves from the virus and, if so, what specific actions they have taken. Responses were coded according to whether people reported taking efforts to distance themselves from others (coded as 1 ) or not (coded as 0 ). This allows us to isolate general efforts to social distance when examining bias toward Asians.

\section{Control variables}

We controlled for a diverse set of demographic indicators that may also impact anti-Asian attitudes, including gender, age, race, education, sexual orientation, political affiliation, and whether people were practicing social distancing.

\section{Analyses}

We tested a regression model to examine the relationships between COVID-19 knowledge and beliefs and anti-Asian attitudes. Variables were entered in two steps in which the first step contained the control variables and the second step added knowledge and fear about COVID-19, feelings of being more unsafe around people from Asian countries in comparison with non-Asian countries with outbreaks of similar severity, trust in science, and trust in President Trump. Analyses were conducted using IBM SPSS Version 26.0 (SPSS 2020). Data are available from the authors upon request.

\section{Results}

\section{Descriptive statistics}

Before testing the predictors of bias toward people of Asian descent, we first calculated descriptive statistics for our bias measure and each of our focal independent variables (see Table 1). Rated on a scale of 1 to 5 with 5 indicating higher levels of bias, participants scored an average of 2.45 $(S D=1.04)$. Participants reported they were the most likely to avoid sitting next to an Asian person $(M=2.66$ $S D=1.35)$ followed by avoiding ordering food prepared by restaurants with Asian employees $(M=2.41, S D=$ 2.41), moving farther away from an Asian person in public $(M=2.38, S D=1.32)$, and limiting interactions with Asian coworkers or customers $(M=2.34, S D=1.32)$. Further, $475(41.6 \%)$ of our participants endorsed that they were somewhat or extremely likely to engage in at least one of the behaviors included in the measure.

Turning to the predictor variables, participants scored an average of $17.29(S D=2.74)$ out of 24 total questions about COVID-19 knowledge and were moderately fearful 


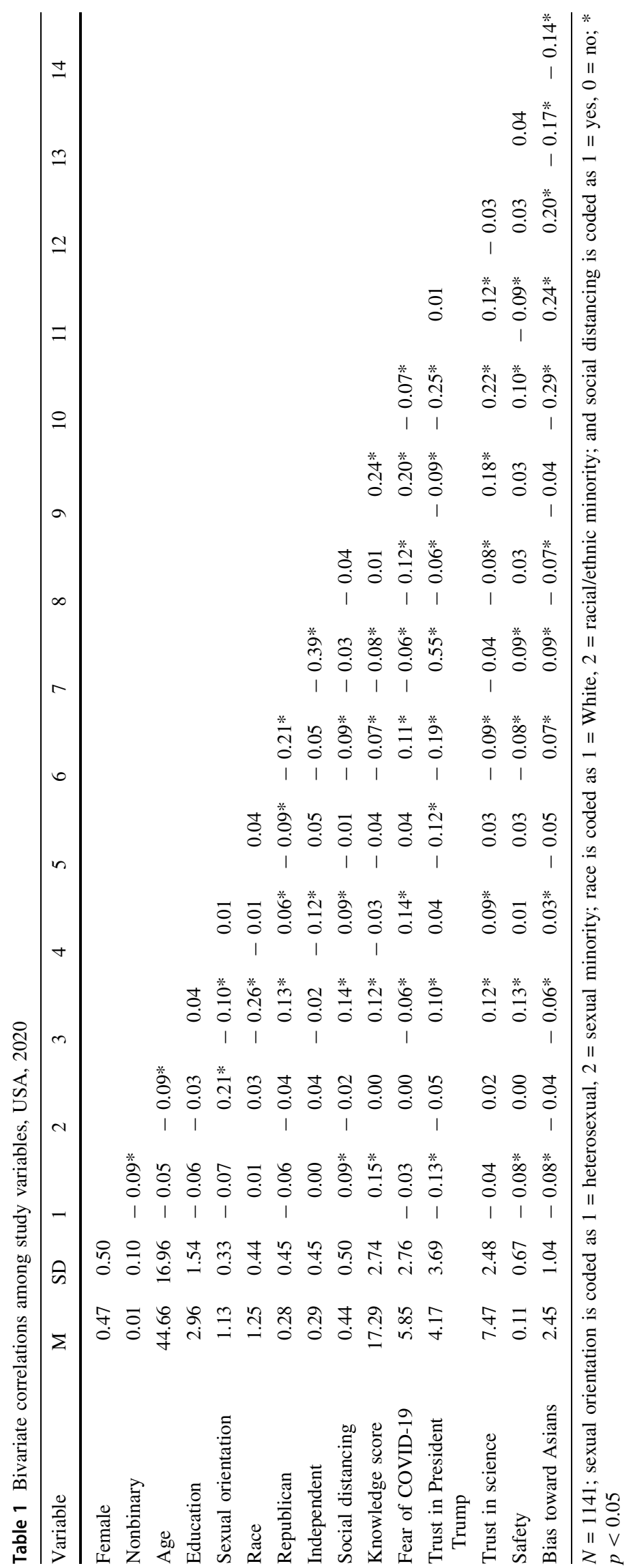


of contracting the virus $(M=5.85, S D=2.76)$. Rated on a scale of 0 to 10 , the average trust rating for science/scientists was $7.47(S D=2.48)$ and the average trust rating for President Trump was $4.17(S D=3.69)$. Finally, on the variable assessing relative perceptions of safety around people from China and South Korea compared to people from Iran and Italy, participants felt slightly less safe around people from Iran and Italy on average $(M=.11$, $S D=.67)$.

\section{Regression results}

Table 2 reports the results from the two-step multivariate regression model predicting bias toward Asians. In Step 1, several control variables were significantly associated with bias toward Asians. Females scored lower on the bias toward Asians scale $(b=-.18, p=0.005)$ as did older adults $(b=-.004, p=0.029)$. Nonwhite individuals $(b=.18, p=0.014)$ and Republicans $(b=.22, p=0.004)$ also reported greater bias. The control variable capturing whether people have engaged in social distancing was unrelated to anti-Asian bias $(b=-.04, p=0.559)$, suggesting our measure of avoidance of Asian people and general efforts to social distance may be distinct.

Results from Step 2 of the model demonstrated a significant positive relationship between fear of COVID-19 and negative attitudes toward Asians $(b=.09, p<0.001)$. This supports the prediction that fear may activate negative intergroup attitudes through perceptions of intergroup threat. Results additionally suggest that knowledge of COVID-19 symptoms and transmission is significantly negatively associated with Asian bias $(b=-.07$, $p<0.001)$, suggesting that less accurate information is related to more negative attitudes toward Asians. Probing our findings related to fear, we also included a variable that captures the degree to which participants felt unsafe around people from the Asian countries with the highest outbreaks in comparison with the non-Asian countries with the highest outbreaks. The safety variable was significantly associated with bias toward Asian people $(b=-.15$, $p<0.001$ ), suggesting that respondents who felt less safe around people from China and South Korea than people from Iran and Italy reported more negative attitudes toward Asian people. Results further showed that participants with greater trust in Donald Trump reported more bias toward Asian people $(b=.04, p<0.001)$ and individuals with more trust in science reported less bias $(b=-.06$, $p<0.001)$.

\section{Discussion}

The current paper sought to empirically examine the negative attitudes toward Asian people that have been prompted by the COVID-19 outbreak as well as the beliefs and fears that may undergird these negative sentiments.

Table 2 Multivariate regression analyses predicting bias toward Asians, USA, 2020

\begin{tabular}{|c|c|c|c|c|c|c|}
\hline \multirow[t]{2}{*}{ Variable } & \multicolumn{3}{|l|}{ Step 1} & \multicolumn{3}{|l|}{ Step 2} \\
\hline & $B$ & SE & $95 \% \mathrm{CI}$ & $B$ & SE & $95 \% \mathrm{CI}$ \\
\hline Female & $-0.175^{* *}$ & 0.062 & $-0.296,-0.054$ & -0.102 & 0.058 & $-0.215,0.011$ \\
\hline Nonbinary & -0.442 & 0.319 & $-1.067,0.184$ & -0.292 & 0.292 & $-0.866,0.281$ \\
\hline Age & $-0.004 *$ & 0.002 & $-0.008,0.000$ & -0.001 & 0.002 & $-0.004,0.003$ \\
\hline Education & 0.012 & 0.020 & $-0.027,0.051$ & -0.007 & 0.018 & $-0.043,0.029$ \\
\hline Sexual orientation & -0.144 & 0.094 & $-0.329,0.040$ & -0.113 & 0.087 & $-0.283,0.058$ \\
\hline Race & $0.183 *$ & 0.074 & $0.037,0.328$ & 0.102 & 0.069 & $-0.033,0.237$ \\
\hline Republican & $0.221 * *$ & 0.077 & $0.070,0.372$ & 0.007 & 0.085 & $-0.161,0.174$ \\
\hline Independent & -0.051 & 0.074 & $-0.196,0.095$ & -0.079 & 0.070 & $-0.217,0.059$ \\
\hline Social distancing & -0.037 & 0.062 & $-0.159,0.086$ & 0.023 & 0.060 & $-0.096,0.141$ \\
\hline \multicolumn{7}{|l|}{$R^{2}=0.032$} \\
\hline Knowledge & & & & $-0.070 * * *$ & 0.011 & $-0.092,-0.048$ \\
\hline Fear & & & & $0.086 * * *$ & 0.011 & $0.065,0.107$ \\
\hline Trust in President Trump & & & & $0.042 * * *$ & 0.010 & $0.023,0.061$ \\
\hline Trust in Science & & & & $-0.063 * * *$ & 0.012 & $-0.086,-0.040$ \\
\hline Safety & & & & $-0.149 * * *$ & 0.043 & $-0.233,-0.066$ \\
\hline$R^{2}\left(\Delta R^{2}\right)=0.191(0.159)$ & & & & & & \\
\hline
\end{tabular}

$* p<0.05 ; * * p<0.01 ; * * * p<0.001$ 
Our results suggest that negative attitudes toward Asian people in response to COVID-19 were somewhat common among our participants, a finding which comports with the growing number of discrimination and harassment allegations brought forward during the pandemic (Zannetou et al. 2020). Given that these negative attitudes may be the cause of the harmful acts befalling Asian Americans, it is critical to understand what may be contributing to such attitudes. We find that greater fear of contracting COVID-19, feelings of being unsafe around people from Asian countries, less accurate knowledge about the virus, and greater trust in President Trump and lower trust in science predict higher levels of bias.

\section{Public health implications}

Our findings underscore the role that public health organizations can play in mitigating harm. Disseminating accurate information on disease transmission can save lives, but it may also disrupt stigmatization and discrimination. Although it is essential for the public to take pandemics seriously, our findings show the harmful role that fear can play in stoking negative out-group sentiments, particularly when that fear becomes associated with a specific social group. Public health organizations were at the forefront of efforts to identify a non-stigmatizing name for the virus, ultimately settling on COVID-19. We argue, however, that public health efforts should not only communicate the (potentially unintended) consequences of emphasizing the origin of the virus but also consider how fear more generally can activate biases based on race, ethnicity, or nationality. Moreover, stable attitudes among the public, such as trust in science, may also shape the way public health crises unfold and our findings suggest that future public health efforts may be bolstered by identifying and addressing these attitudes.

As in previous infectious disease outbreaks, findings from this study highlight that stigmatized groups may be uniquely vulnerable, both because of the physical threat posed and because of the detrimental effects of discriminatory experiences on mental health and chronic stress processes (Gee et al. 2007). As such, the public health impacts of COVID-19 may be unequally distributed across the population. Additional support services and protections should be made available for people of Asian descent, and public health efforts should expand to focus on reducing implicit and explicit biases among the general population.

\section{Limitations and future directions}

Though this study represents the first systematic attempt to empirically examine bias toward Asian people amid the COVID-19 outbreak, there are also limitations. First, data were collected from participants in the USA and Hispanic Americans were underrepresented in the sample, potentially limiting generalizability. Negative treatment of people of Asian descent has also been documented in other countries, and additional efforts are needed to assess bias outside of the US context and determine whether the predictors from the current study generalize to other populations. Further, bias may manifest in behaviors not captured in our study and our findings may therefore offer a truncated view of the ways people may express bias toward Asian people. In particular, the current study did not capture implicit attitudes toward people of Asian descent, and it is possible that some negative attitudes may be unconscious or unintentional. Subsequent work should incorporate implicit bias measures. Social desirability may also have influenced the extent to which respondents expressed bias, suggesting the levels of bias reported here may be underestimated.

Finally, there may be additional variables outside of those explored in the current study that predict anti-Asian bias in response to COVID-19. For example, xenophobic attitudes, or a general fear and distrust of outsiders, may make people more susceptible to associating the virus with people of Asian descent. Additionally, bias in response to COVID-19 may also be higher among people who hold essentialist beliefs, or beliefs that members of a racial or social group share a defining essence that makes all members the same as one another and essentially different from members of other groups (Fairchild et al. 1995; No et al. 2008). Such beliefs may strengthen the perceived similarity of all members of Asian cultures and lead to blaming all members of the cultural group. Future research is encouraged to explore these and other variables.

\section{Conclusion}

The recent outbreak of the novel coronavirus has had substantive impacts that have permeated physical, economic, mental, and social well-being. Although it is technically true that all are vulnerable to the wide-reaching effects of COVID-19, individuals of Asian descent may carry a unique burden due to the bias that has been activated by COVID-19. Public health campaigns have worked to uncouple the virus from its origin in China, but must also confront fear associated with the virus, lack of knowledge about how it spreads, and lack of trust in science in order to reduce bias. These factors may evoke negative attitudes toward Asian people and increase exposure to prejudice and discrimination.

Funding This study did not receive funding. 


\section{Compliance with ethical standards}

Conflict of interest The authors declare that they have no conflict of interest.

Ethical approval All procedures performed in studies involving human participants were in accordance with the ethical standards of the institutional review board at Ohio University (\#) and with the 1964 Helsinki declaration and its later amendments or comparable ethical standards.

Informed consent Informed consent was obtained from all individual participants included in the study.

\section{References}

Allport GW (1954) The nature of prejudice. Addison-Wesley, Cambridge, MA

Barrett R, Brown PJ (2008) Stigma in the time of influenza: social and institutional responses to pandemic emergencies. J Infect Dis 197:S34-S37. https://doi.org/10.1086/524986

Centers for Disease Control and Prevention (2020) Social distancing, quarantine, and isolation. In: Coronavirus disease 2019. https:// www.cdc.gov/coronavirus/2019-ncov/prevent-getting-sick/ social-distancing.html. Accessed 10 Apr 2020

Chang J (2020) San Francisco Chinatown affected by coronavirus fears, despite no confirmed cases: NPR. NPR

Des Jarlais DC, Galea S, Tracy M et al (2006) Stigmatization of newly emerging infectious diseases: AIDS and SARS. Am J Public Health 96:561-567. https://doi.org/10.2105/AJPH.2004.054742

Di Giuseppe G, Abbate R, Albano L et al (2008) A survey of knowledge, attitudes and practices towards avian influenza in an adult population of Italy. BMC Infect Dis. https://doi.org/10. 1186/1471-2334-8-36

Eichelberger L (2007) SARS and New York's Chinatown: the politics of risk and blame during an epidemic of fear. Soc Sci Med 65:1284-1295. https://doi.org/10.1016/j.socscimed.2007.04.022

Fairchild HH, Yee AH, Wyatt GE, Weizmann FM (1995) Readdressing psychology's problems with race. Am Psychol 50:46-47. https://doi.org/10.1037/0003-066X.50.1.46

Gee GC, Spencer M, Chen J et al (2007) The association between self-reported racial discrimination and 12-month DSM-IV mental disorders among Asian Americans nationwide. Soc Sci Med 64:1984-1996. https://doi.org/10.1016/j.socscimed.2007.02.013

Goodwin R, Haque S, Neto F, Myers LB (2009) Initial psychological responses to Influenza A, H1N1 ("Swine flu"). BMC Infect Dis 9:166. https://doi.org/10.1186/1471-2334-9-166

Hetherington MJ (1998) The political relevance of political trust. Am Political Sci Rev 92(4):791-808

Hoppe T (2018) "Spanish flu": when infectious disease names blur origins and stigmatize those infected. Am J Public Health 108:1462-1464. https://doi.org/10.2105/AJPH.2018.304645

Johns Hopkins University \& Medicine (2020) COVID-19 mapJohns Hopkins Coronavirus Resource Center. In: Coronavirus Resource Center. https://coronavirus.jhu.edu/map.html. Accessed 10 Apr 2020

Khan MS, Osei-Kofi A, Omar A et al (2016) Pathogens, prejudice, and politics: the role of the global health community in the European refugee crisis. Lancet Infect Dis 16:e173-e177

Lavrakas PJ (ed) (2008) Feeling thermometer. In: Encyclopedia of survey research methods

Lee J, Murphy D (2003) The SARS epidemic: Asian-Americans; In U.S., fear is spreading faster than SARS. https://www.nytimes. com/2003/04/17/world/the-sars-epidemic-asian-americans-in-usfear-is-spreading-faster-than-sars.html. Accessed 6 Jul 2020
Leung C, Guan J (2004) Yellow peril revisited: impact of SARS on the Chinese and Southeast Asian Canadian communities

Loffman M (2020) Asian Americans describe 'gut punch' of racist attacks during coronavirus pandemic I PBS NewsHour. PBS

Maragakis LL (2020) Coronavirus disease 2019: myth vs. fact I Johns Hopkins Medicine. In: Johns Hopkins Medicine. https://www. hopkinsmedicine.org/health/conditions-and-diseases/corona virus/2019-novel-coronavirus-myth-versus-fact. Accessed 28 Mar 2020

Marquardt A, Hansler J (2020) US push to include "Wuhan virus" language in G7 joint statement fractures alliance-CNNPolitics. $\mathrm{CNN}$

McCauley M, Minsky S, Viswanath K (2013) The H1N1 pandemic: media frames, stigmatization and coping. BMC Public Health 13:1116. https://doi.org/10.1186/1471-2458-13-1116

Miller DA, Smith ER, Mackie DM (2004) Effects of intergroup contact and political predispositions on prejudice: role of intergroup emotions. Gr Process Intergr Relat 7:221-237. https://doi.org/10.1177/1368430204046109

Mullis S, Glenn H (2020) New site collects reports of racism against Asian Americans amid coronavirus pandemic: coronavirus live updates: NPR. NPR

No S, Hong YY, Liao HY et al (2008) Lay theory of race affects and moderates Asian Americans' responses toward American culture. J Personal Soc Psychol 95:991-1004. https://doi.org/10. 1037/a0012978

Person B, Sy F, Holton K et al (2004) Fear and stigma: the epidemic within the SARS outbreak. Emerg Infect Dis 10:358-363

Rogers K, Jakes L, Swanson A (2020) Trump defends using 'Chinese Virus' label, ignoring growing criticism-The New York Times. In: New York Times. https://www.nytimes.com/2020/03/18/us/ politics/china-virus.html. Accessed 2 Jun 2020

Ruiz NG, Horowitz JM, Tamir C (2020) Many Black, Asian Americans say they have experienced discrimination amid Coronavirus I Pew Research Center. In: Pew Research Center. https://www.pewsocialtrends.org/2020/07/01/many-black-andasian-americans-say-they-have-experienced-discriminationamid-the-covid-19-outbreak/?fbclid=IwAR3FjmrkiVLlCbVZ t8UwML3HowDXcnM5Pzxs16rbTd8yN6D1zoBguZx45-I. Accessed 6 Jul 2020

Sherif M, Sherif CW (1969) Ingroup and intergroup relations: experimental analysis. In: Sherif M, Sherif CW (eds) Social osychology. Harper \& Row, New York, pp 221-266

SPSS Statistics-Overview I IBM. https://www.ibm.com/products/ spss-statistics. Accessed 6 Mar 2020

Stephan WG, Ybarra O, Morrison MR (2009) Intergroup threat theory. In: Nelson TD (ed) Handbook of prejudice, stereotyping, and discrimination. Taylor \& Francis, New York, NY

Tajfel HC, Turner JC (1986) The social identity theory of intergroup behavior. In: Worchel S, Austin WG (eds) Psychology of intergroup relations. Nelson-Hall, Chicago, pp 7-24

Tavernise S, Oppel RAJ (2020) Spit on, yelled at, attacked: chineseamericans fear for their safety-The New York Times. New York Times

World Health Organization (2020) Coronavirus disease (COVID-19) advice for the public: myth busters. https://www.who.int/ emergencies/diseases/novel-coronavirus-2019/advice-for-public/ myth-busters. Accessed 28 Mar 2020

Zannetou S, Baumgartner J, Finkelstein J, Goldenberg A (2020) WEAPONIZED INFORMATION OUTBREAK: a case study on COVID-19, bioweapon myths, and the asian conspiracy memeNetwork Contagion Research Institute

Publisher's Note Springer Nature remains neutral with regard to jurisdictional claims in published maps and institutional affiliations. 